\title{
KOMBINASI LASER Q-SWITCHED Nd:YAG (1064 nm) DAN TRETINOIN TOPIKAL 0,025\% PADA PENGHAPUSAN TATO : SEBUAH LAPORAN KASUS
}

\author{
Sinta Murlistyarini ${ }^{\star}$ Yustian Devika Rakhmawati ${ }^{\star 凶}$
}

\begin{abstract}
Abstrak
Tato merupakan suatu tanda permanen atau desain yang dibuat di tubuh dengan memasukkan pigmen warna ke dalam lapisan dermis kulit melalui luka di lapisan atas kulit. Saat ini teknik laser menjadi pilihan efektif untuk penghapusan tato terutama laser Q-switched dengan konsep fototermolisis selektif. Jenis terapi lain yaitu topikal tretinoin melalui mekanisme pengelupasan superfisialis pada lapisan epidermis yang berperan dalam penghapusan tato. Sejauh pengamatan penulis bahwa di Indonesia belum didapatkan laporan kasus penghapusan tato dengan teknik kombinasi antara laser Nd:YAG $1064 \mathrm{~nm}$ dan tretinoin topikal $0,025 \%$. Dilaporkan kasus seorang laki-laki 40 tahun dengan keluhan penghapusan tato. Pasien diterapi dengan laser Q-switched Nd-YAG $1064 \mathrm{~nm}$ kombinasi dengan tretinoin topikal 0,025\%. Kemudian didapatkan adanya tingkat pembersihan tato dalam derajat ringan $25-50 \%$. Skala VAS nyeri pada sesi pertama dan sesi kedua adalah 3 dan 5 . Tidak ditemukan efek samping yang berarti seperti terbentuknya jaringan parut. Terapi laser menyebabkan target destruksi terbatas hanya pada pigmen tato sehingga meminimalkan kerusakan pada epidermis, dermis, dan jaringan pendukung kulit, dengan tinta tato sebagai kromofor eksogen berperan sebagai molekul target laser. Efek laser akan ditingkatkan dengan kombinasi tretinoin topikal yang mempunyai efek pengelupasan secara superfisial. Teknik kombinasi antara laser Nd:YAG $1064 \mathrm{~nm}$ dan tretinoin topikal 0,025\% dapat dipertimbangkan sebagai salah satu metode yang cukup efektif dalam penghapusan tato.
\end{abstract}

Kata kunci : laser Q-switched Nd:YAG, penghapusan tato, tretinoin topikal.

\section{THE COMBINATION OF Q-SWITCHED Nd:YAG LASER (1064 nm) AND TOPICAL TRETINOIN $0.025 \%$ AS TATTOO REMOVAL THERAPY : A CASE REPORT}

\begin{abstract}
A tattoo is a permanent sign or design made in the human body by inserting pigment into the dermis through a wound in the upper layer of the skin. Laser technology has become an effective choice for tattoo removal, especially Q-switched laser with the concept of selective photothermolysis. Another type of therapy is topical tretinoin by the superficial peeling mechanism of the epidermal layer which plays a role in tattoo removal. So far, there has not been reported a case of tattoo removal using a combination of Nd:YAG laser $1064 \mathrm{~nm}$ and topical tretinoin $0,025 \%$ in Indonesia. We reported a 40 years old man who wants to remove the tattoo. The patient is treated using Q-switched laser Nd-YAG (QSNY) $1064 \mathrm{~nm}$ combination with topical tretinoin $0,025 \%$. Mild tattoo clearance level is $25-50 \%$. The pain scale on VAS in the first and second sessions is 3 and 5 . There are no significant side effects such as scarring. This case indicated that laser causes limited destruction target to the tattoo pigment and causes minimal damage to the epidermis, dermis, and skin appendages. The tattoo's ink as exogenous chromophore plays a role as a laser target molecules. The laser effect is enhanced by the combination of topical tretinoin which has a superficial exfoliating effect. The combination of Q-Switched Nd:YAG laser $1064 \mathrm{~nm}$ and topical tretinoin 0,025\% in tattoo removal can be considered a fairly effective technique.
\end{abstract}

Keywords: Q-switched laser Nd:YAG, tattoo removal, topical tretinoin.

* Departemen/SMF Dermatologi dan Venereologi, Fakultas Kedokteran, Universits Brawijaya/RSUD Dr. Saiful Anwar Malang

E-mail: yustian85dr@gmail.com 


\section{Pendahuluan}

Tato merupakan suatu tanda permanen atau desain yang dibuat di tubuh dengan cara memasukkan pigmen warna ke dalam lapisan dermis kulit melalui luka di lapisan atas kulit. ${ }^{1}$ Tato ditempatkan dengan menyuntikkan partikel tinta atau pigmen eksogen (ukuran bervariasi 20-400 nm) ke dalam dermis. Selama proses tato, epidermis dan dermis papiler atas akan dihomogenisasi dan partikel tinta didistribusikan secara ekstraselular maupun intraselular. 2,3

Sebuah studi di Amerika Serikat menyebutkan bahwa prevalensi tato pada populasi remaja mengalami kenaikan dari 16\% pada tahun 2003 menjadi 21\% pada tahun 2012. Demikian juga di Jerman diketahui populasi usia kisaran 18-30 tahun sekitar 25\% memiliki tato. Diperkirakan sekitar $6 \%$ dari populasi ini menginginkan penghapusan tato setelah 10-15 tahun. 2,4

Beberapa modalitas terapi telah dilakukan seperti dermabrasi, destruksi kimiawi, bedah beku, bedah listrik, dan eksisi bedah, namun sering tidak memberikan hasil yang memuaskan serta beberapa efek samping jaringan parut. Teknik laser menjadi pilihan efektif saat ini untuk penghapusan tato terutama laser Q-switched. Mekanisme dasar melalui destruksi target dari pigmen tato menggunakan panjang gelombang spesifik dengan konsep fototermolisis selektif. $2,4,5$
Topikal tretinoin menunjukkan mekanisme pengelupasan superfisialis pada lapisan epidermis yang berperan dalam penghapusan tato. 6,7

Dilaporkan seorang laki-laki usia empat puluh tahun dengan keluhan ingin menghapus tato pada lengan kiri atas dan diterapi dengan laser Q-switched Nd:YAG $1064 \mathrm{~nm}$ dan kombinasi dengan tretinoin topikal $0.025 \%$. Tujuan dari laporan ini untuk melihat efektivitas dari terapi kombinasi antara laser Q-switched Nd:YAG 1064 nm dan tretinoin topikal $0,025 \%$ untuk menghapus tato.

\section{Kasus}

Seorang laki-laki, berusia empat puluh tahun, datang berobat ke Poliklinik Dermatologi dan Venereologi Rumah Sakit Umum Daerah Dr. Saiful Anwar Malang dengan keluhan ingin menghilangkan tato di lengan tangan kiri atas. Pasien mengaku sejak tahun 2000 mulai melakukan tato pada lengannya di tempat pembuatan tato yang tidak profesional. Tato pasien berwarna hitam dan biru (Gambar 1). Pada tahun 2017, pasien pernah mencoba menghilangkan tato di tempat yang tidak profesional, namun belum tampak memudar. Pasien tidak memiliki riwayat muncul jaringan parut bila mengalami luka.

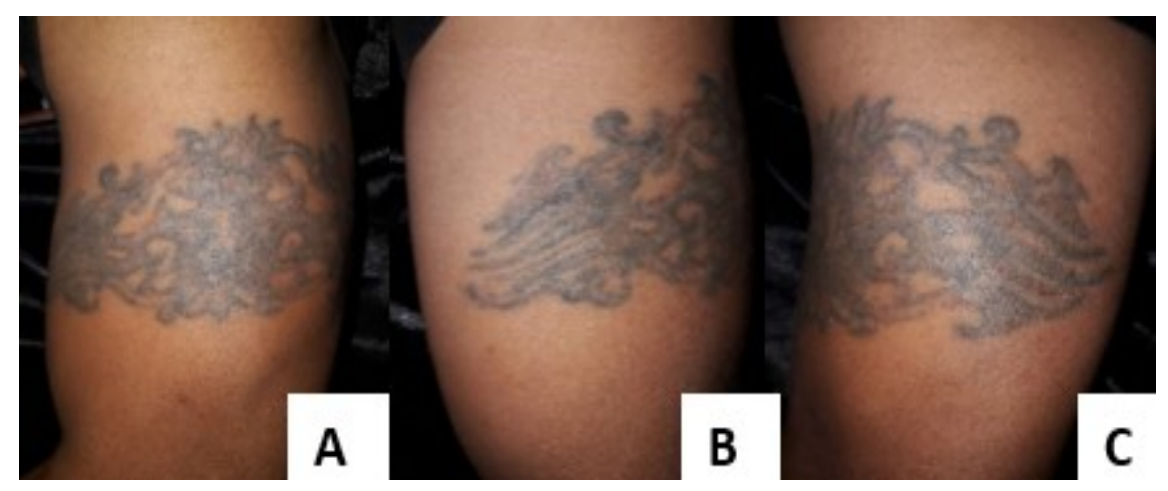

Gambar 1. Gambaran tato pada lengan kiri atas bagian anterior (A), gambaran tato pada lengan kiri atas bagian medial $(B)$, gambaran tato pada lengan kiri atas bagian lateral $(C)$. 
Pemeriksaan status dermatologis area lengan tangan kiri bagian atas tampak patch hiperpigmentasi bentuk tulisan, berbatas tegas. Pasien didiagnosis dengan tattoo removal. Pasien direncanakan terapi menggunakan laser Q-switched Nd-YAG (QSNY) $1064 \mathrm{~nm}$. Alat dan bahan yang disiapkan berupa cleanser, krim anestesi topikal mengandung 2,5\% lidocaine/ prilocaine, kapas alkohol, kasa steril, larutan normal salin, laser Q-switched Nd-YAG (QSNY) 1064 nm (Mermaid®) (Gambar 2AB).

Pasien diposisikan berbaring dan lengan dibersihkan menggunakan cleanser. Anestesi topikal dioleskan merata di seluruh area tato pada lengan tangan kiri atas, dibiarkan hingga 30 menit, lalu dibersihkan dengan kasa. Area tato didisinfeksi dengan kapas alkohol dan dibiarkan mengering. Kemudian dilakukan laser QSNY mengikuti pola tato dengan pengaturan: panjang gelombang $1064 \mathrm{~nm}$, spot size $5 \mathrm{~mm}$, fluence dimulai dari $300 \mathrm{~mJ}$ kemudian dinaikkan sampai $900 \mathrm{~mJ}$ untuk mencapai end point, replication rate 5 $\mathrm{Hz}$, dengan end point berupa pin point bleeding (Gambar 3A-C). Skala nyeri VAS pasien sesaat setelah prosedur laser adalah 3.

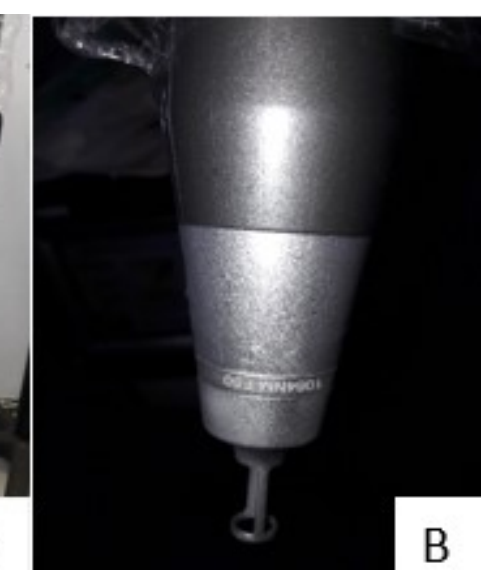

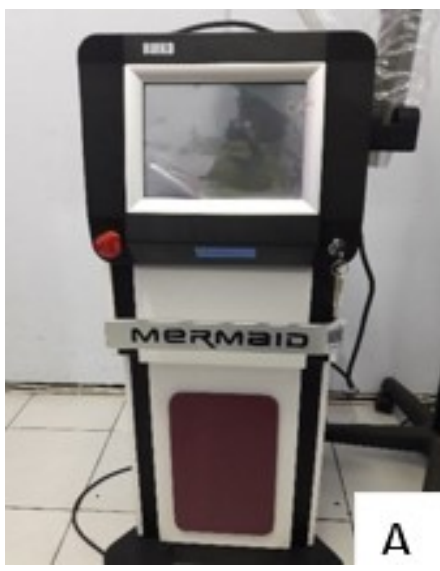

Gambar 2: Laser Q-switched Nd laser: YAG 1064 nm.
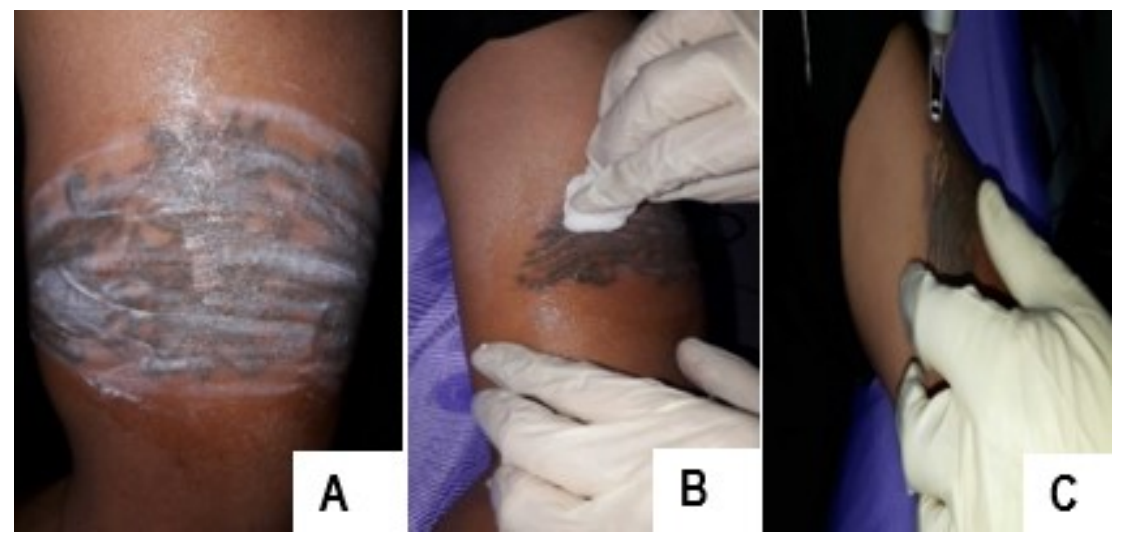

Gambar 3. A. Aplikasi anestesi topikal pada area tato, B. Area tato dibersihkan dengan normal saline, C. Prosedur tato mengikuti pola tato. 
Setelah selesai proses terapi laser, area tato dikompres menggunakan kasa yang dibasahi dengan normal salin selama 15 menit. Kemudian diberikan asam mefenamat oral $3 \times 500 \mathrm{mg}$ untuk meredakan rasa nyeri dan topikal Tretinoin $0,025 \%$ malam hari mulai hari keempat setelah laser.

Pada hari kedua setelah terapi laser, pasien mengaku muncul lepuh-lepuh berisi cairan bening pada beberapa area tato. Tidak terasa nyeri ataupun gatal. Dalam waktu kurang lebih 2 hari lepuh tampak mengempis, kering, meninggalkan area krusta kehitaman. Kemudian krusta mengelupas dan meninggalkan area yang sewarna dengan warna kulit dan beberapa area hipopigmentasi. Penilaian tingkat clearance tato setelah laser sesi pertama dan setelah laser sesi kedua dengan mengikuti grading yaitu $1=$ tidak ada/ minimal ( $<25 \%$ tato $), 2=$ ringan $(25-50 \%)$, $3=$ bagus $(51-75 \%), 4=$ sangat bagus $(>75 \%)$.

Pada pasien didapatkan tingkat clearance tato setelah sesi kedua adalah derajat ringan yaitu $25-50 \%$. Skala VAS (Visual Analogue Score) nyeri pada sesi pertama dan sesi kedua adalah 3 dan 5 . Tidak didapatkan efek samping yang berarti seperti terbentuknya jaringan parut, seperti yang tampak pada gambar 4A-C.

\section{Pembahasan}

Tato merupakan tanda atau desain permanen yang dibuat dengan cara menyuntikkan partikel tinta atau pigmen eksogen (ukuran bervariasi 20-400 nm) ke dalam dermis. Selama proses tato, epidermis dan dermis papiler atas akan dihomogenisasi dan partikel tinta didistribusikan secara ekstraselular maupun intraselular. Setelah 2-3 bulan, lapisan kulit akan terbangun kembali sedangkan partikel tinta tetap terkonsentrasi di dalam fibroblast di bawah lapisan jaringan parut di dermis. Penggunaan tinta tato tidak diatur oleh Food and Drug Administration (FDA) dan sebagian besar pasien tidak mengetahui unsur-unsur yang digunakan di dalam tinta tato. ${ }^{2,3}$

Terdapat beberapa tipe tato yang berbeda yaitu tato dekoratif, tato kosmetik, tato traumatik, dan tato medis. Di antara tipe tersebut tato dekoratif adalah yang paling umum digunakan. Tipe tato ini dibagi lagi menjadi tato amatir yang biasanya dilakukan dengan tangan dengan menggunakan bantuan kawat atau jarum, serta tato profesional yang menggunakan suatu alat yang disebut "tattoo gun".,2,3
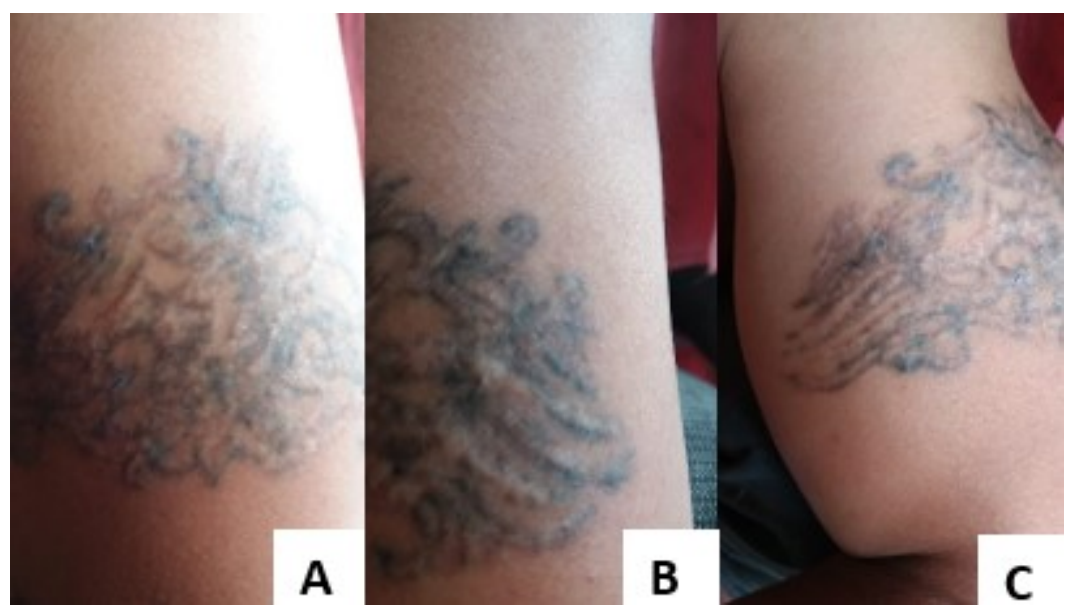

Gambar 4. Evaluasi pada minggu kedua setelah terapi laser seri kedua pada area tato anterior (A), medial (B), dan lateral (C). 
Warna tato yang paling umum digunakan adalah warna hitam. Namun, pada beberapa tahun terakhir tato berwarna menggunakan warna merah, biru, hijau, dan kuning diketahui semakin umum dan populer. ${ }^{7}$ Pada kasus ini, pasien melakukan proses tato dengan tipe tato amatir atau nonprofesional dengan warna hitam dan biru.

Berbagai modalitas terapi untuk penghapusan tato telah digunakan seperti eksisi, bedah beku, dermabrasi, bedah listrik, koagulasi infra merah, maupun ablasi dengan laser $\mathrm{CO}_{2}$. Namun, modalitas tersebut sering memberikan hasil penghapusan yang tidak sempurna ataupun berbagai derajat jaringan parut. Seperti tindakan bedah eksisi yang dapat meninggalkan jaringan parut dalam ukuran besar dan dapat menyebar karena tato biasanya berlokasi di daerah akral.4,5,6,7

Perkembangan teknologi saat ini melibatkan penggunaan laser Q-switched untuk penghapusan tato. ${ }^{7}$ Laser (Light Amplification by Stimulated Emission of Radiation) merupakan sumber cahaya monokromatik yang koheren dengan intensitas tinggi yang dapat digunakan untuk terapi berbagai kondisi dermatologis. ${ }^{8}$ Laser pada bidang dermatologi bekerja pada berbagai spektrum panjang gelombang yaitu spektrum ultraviolet $(10-400 \mathrm{~nm})$, spektrum cahaya tampak (400-720nm), dan spektrum inframerah (720-10.600nm). Beberapa jenis laser di antaranya adalah Er:YAG $(2940 \mathrm{~nm})$, laser karbondioksida/ $\mathrm{CO}_{2} \quad(10.600 \mathrm{~nm})$, $\mathrm{Nd}$ :YAG (512nm dan 1064nm), Ruby (694nm), Alexandrite $(755 \mathrm{~nm})$, Diode (810nm), dan pulse dye laser (595nm). Masing-masing jenis laser bekerja dengan panjang gelombang, densitas energi, karakter pulse serta indikasi yang berbeda. Indikasi penggunaan laser misalnya pada kasus peremajaan kulit, gangguan pigmentasi, (misalnya lentigo, efelid, melasma), gangguan vaskular (misalnya telangiektasis, eritema, cherry angioma), penghapusan tato, dan penghilangan rambut. ${ }^{3}$
Penggunaan laser memiliki prinsip kerja fototermolisis selektif yaitu ketika panjang gelombang energi tertentu dilepaskan dalam jangka waktu yang lebih pendek dari thermal relaxation time (TRT) pada kromofor target, energi akan ditahan di sel target dan menyebabkan lebih sedikit kerusakan pada daerah sekitarnya. ${ }^{9}$ Kromofor merupakan suatu kelompok atom atau elektron bagian dari molekul organik yang bertanggung jawab terhadap warnanya. Kromofor di area dermal yang umum adalah air, hemoglobin, oksihemoglobin, kolagen, melanin, dan beta karoten.6,10 Tinta tato merupakan suatu kromofor eksogen yang dapat menjadi molekul target terhadap terapi laser sesuai panjang gelombang. Pigmen tato mempunyai ukuran yang sangat kecil, sehingga hanya membutuhkan durasi pulse nanosecond saja untuk dapat dirusak. 4,7

Warna tinta yang berbeda secara istimewa diserap oleh panjang gelombang cahaya tertentu. Ketika energi laser diaplikasikan pada kulit lalu diubah menjadi panas di dalam partikel tinta tato, maka akan menyebabkan partikel-partikel besar terfragmentasi dan rupturnya kapsul fibrosa di sekeliling tinta. Partikel kecil dari tinta kemudian akan dieliminasi melalui proses drainase limfatik dan fagositosis makrofag. Jaringan kulit di sekelilingnya hanya akan menyerap energi secara minimal dan tetap tidak terpengaruh. ${ }^{3}$ Mekanisme lain dari penghapusan tato selain destruksi langsung melalui panas, juga diduga melalui proses fotokimia yaitu pembelahan molekul pigmen oleh iradiasi laser dan oksidasi atau melalui proses fotoakustik yaitu pemecahan molekul berdasarkan gelombang akustik atau tekanan. $^{7}$

Laser yang mampu memproduksi ledakan cahaya dalam waktu singkat disebut quality-(Q-) switched (QS). ${ }^{11}$ Tipe laser Qswitched berbeda sesuai dengan warna tintanya. 
Q-switched Nd:YAG laser $1064 \mathrm{~nm}$ ideal untuk tinta warna hitam dan gelap. Q-switched $\mathrm{Nd}$ :YAG laser $532 \mathrm{~nm}$ efektif untuk tinta warna merah, kuning, dan jingga. Q-switched Alexandrite laser $755 \mathrm{~nm}$ untuk tinta warna hitam, hijau, biru gelap. Serta, Q-switched Ruby laser $694 \mathrm{~nm}$ lebih efektif untuk warna hijau. 3,7

Studi yang dilakukan oleh Pinto et al. (2017) pada 21 pasien dengan tato warna hitam yang diterapi Q-switched Nd:YAG 1064 $\mathrm{nm}$ sebanyak 2 sesi dengan interval 6 minggu. Didapatkan perbaikan yang efektif sebesar 25\% dengan efek samping yang tidak signifikan baik hipo maupun hiperpigmentasi. ${ }^{4}$ Studi lain oleh Zhang et al. (2018) pada 32 pasien dengan tato kosmetik eyeliner warna hitam yang diterapi laser Q-switched Nd:YAG $1064 \mathrm{~nm}$. Setelah terapi 1 sesi didapatkan clearance sebesar grade 3 yaitu $51-75 \%$ pada 21 pasien. ${ }^{12}$

Beberapa hal yang perlu diperhatikan sebelum memulai terapi dengan laser yaitu menentukan tipe kulit dan tipe tato, lokasi dan ukuran tato, riwayat adanya keloid atau jaringan parut yang berhubungan dengan evaluasi efek samping yang mungkin timbul setelah terapi laser. Pemberian anestesi juga diperhatikan karena terapi ini cukup memberikan rasa nyeri meskipun dapat dilakukan dengan cepat. Krim anestesi topikal yang mengandung lidokain, tetrakain, atau prilokain dapat diaplikasikan pada area tato dan dibiarkan sampai berpenetrasi selama 30-45 menit sebelum terapi laser dimulai.2,3

Secara umum teknik laser pada tato dengan memindahkan ujung laser secara halus melintasi pola tinta tato pada kulit. kemudian menutup tato secara bersamaan dengan menempatkan pulse tato berdekatan satu sama lain namun dengan tumpang tindih yang minimal. Timbulnya diskolorisasi warna putih adalah efek yang langsung timbul sesaat setelah laser dikenakan pada tinta tato. Begitu juga dengan efek eritema dan edema yang mungkin muncul setelah terapi. ${ }^{3}$
Pada pasien didapatkan timbulnya blister setelah terapi laser. Hal ini termasuk dalam efek samping yang tidak diinginkan walaupun hanya sementara dan dapat mengalami perbaikan dalam beberapa hari. ${ }^{4}$

Pada sebuah laporan kasus oleh Chiang et al. (1999) didapatkan adanya perbaikan penghapusan pada tato kosmetik eyeliner seorang wanita 31 tahun ras hispanik dengan menggunakan topikal tretinoin $0,025 \% \cdot{ }^{13}$ Suatu penelitian eksperimental oleh Solis et al. (2002) pada marmut yang ditato kemudian diberikan topikal tretinoin gel $0,025 \%$ setiap 6 jam selama periode 7 hari. Setelah itu, dilakukan analisis histopatologi pada hari ke-7 dan didapatkan clearance pigmen hitam dan hijau meskipun ringan. ${ }^{14}$ Diduga cara kerja tretinoin pada penghapusan tato melalui pengelupasan lapisan epidermis kulit. ${ }^{13,14}$

\section{Kesimpulan}

Pada kasus ini, pasien dengan tato warna hitam dan biru gelap diterapi kombinasi antara laser Q-switched Nd:YAG $1064 \mathrm{~nm}$ dan tretinoin topikal 0,025\%. Sehingga, diharapkan dengan dua kombinasi akan didapatkan hasil yang efektif. Pada pasien dilakukan $2 x$ sesi laser dengan interval waktu 5 minggu dan diberi tambahan tretinoin topikal $0,025 \%$ yang dioles malam hari setelah hari ke-4 post laser. Pada evaluasi 2 minggu setelah sesi laser kedua didapatkan hasil yang cukup efektif dengan derajat perbaikan clearance tato pada pasien sebesar $25-50 \%$.

\section{Saran}

Kombinasi terapi antara laser Qswitched Nd:YAG $1064 \mathrm{~nm}$ dan tretinoin topikal $0,025 \%$ dapat dipertimbangkan sebagai salah satu pilihan modalitas terapi pada kasus penghapusan tato yang berwarna hitam dan biru gelap, meskipun masih dibutuhkan evaluasi lebih lanjut. 


\section{Daftar Pustaka}

1. Al-Saadi A and Mahmood AS. Treatment of Skin Hyperpigmentation Using QSwitched (1064 nm and $532 \mathrm{~nm}$ ) Nd:YAG Laser. Iraqi Journal of Laser. 2016; 15(B): 1-7.

2. Ho SGY and Goh CL. Laser Tattoo Removal: A Clinical Update. Journal of Cutaneous and Aesthetic Surgery. 2015; 8 (1):1-15.

3. Small R and Hoang D. A Practical Guide to Laser Procedure. Philadelphia: Wolters Kluwer. 2016.

4. Pinto F, Buning $G$, Karsai S, Weib C, Baumler W, Hammes $S$ et al. Neodymium -Doped Yttrium Aluminium Garnet (Nd:YAG), 1064-nm Picosecond Laser vs. $\mathrm{Nd}$ :YAG 1064-nm Nanosecond Laser in Tattoo Removal: A Randomized Controlled Single-Blind Clinical Trial. British Journal of Dermatology. 2017; 176:45764.

5. Leu FJ, Huang $C L$, Sue YM, Lee SC, Wang CC. Effect of Tattoo Ink's Absorption Spectra and Particle Size on Cosmetic Tattoo Treatment Efficacy Using QSwitched Nd:YAG Laser. Laser Med Sci. 2015; 30:303-09.

6. Mankowska A, Kasprzak W, Adamski Z. Long-Term Evaluation of Ink Clearance in Tattoos with Different Color Intensity Using The 1064-nm Q-Switched Nd:YAG Laser. Journal of Cosmetic Dermatology. 2015; 14:302-09.
7. Choudhary S, Elsaie ML, Leiva A, Nouri K. Lasers for Tattoo Removal: A Review. Lasers Med Sci. 2010; 25:619-27.

8. Sarkar R, Arora P, Garg VK, Sonthalia S, Gokhale N. Melasma Update. Indian Dermatology Online Journal. 2014; 5(4):426.

9. Karn D, Amatya A, Razouria EA, Timalsina M, Suwal A. Q-Swithed NeodymiumDoped Yttrium Aliminium Garnet Laser Therapy for Pigmented Skin Lesions : Efficacy and Safety. Kathmandu Univ Med J. 2012; 10(2):46-50.

10. Rajesh S, Anvita D, Vikas P, Dilip G, Pal JA. Cromophore - an Utility in UV Spectrophotometer. Inventi Journals. 2012; 3:1-5.

11. Goldberg DJ. Laser Dermatology. Massachusetts : Blackwell Publishing; 2008

12. Mengli Z, Yuqing $H$, Tong L, Qiuju W. Comparison of Treatment with an Alexandrite Picosecond Laser and Nd:YAG Nanosecond Laser for Removing Blue-Black Chinese Eyeliner Tattoos. Journal Cosmetic and Laser Therapy. 2018; 1-5.

13. Chiang JK, Barsky S, Bronson DM. Tretinoin in the Removal of Eyeliner Tattoo. Journal of The American Academy of Dermatology. 1999; 40(6):1-3.

14. Solis RR, Diven DG, Colome-Grimmer MI, Snyder Ned 4th, Wagner RF. Experimental Nonsurgical Tattoo Removal in a Guinea Pig Model with Topical Imiquimod and Tretinoin. Dermatol Surg. 2002; 28: 83-87. 